Pensamiento Crítico Vol. 19 N$^{\circ} 1$, pp. 7-32

\title{
El TPP, la inclusión de nuevos miembros y el futuro del APEC
}

The TTP, the inclusion of new members and the future of APEC

Carlos Aquino Rodríguez ${ }^{1}$

\section{RESUMEN}

Este año se espera terminar las negociaciones del TPP (aunque esto no parece fácil), que sería uno de los acuerdos de liberalización más ambiciosos pues no dejaría ningún sector de la economía fuera de ese proceso. Del 22 al 25 de febrero y otra vez el 19 y 20 de mayo se realizaron en Singapur reuniones de ministros de Comercio y jefes de los equipos negociadores de los países miembros del TPP, pero al término de esas reuniones quedaron todavía pendientes varios temas.

Se considera que el TPP podría ser una vía para finalizar el propio proceso de liberalización entre las 21 economías del APEC.

En este artículo se analiza el proceso de liberalización del TPP, empezando primero con describir qué es el TPP; en segundo término se ven los puntos que negocia el TPP, especialmente los más contenciosos; en tercer lugar se ve que es lo que el Perú puede ganar de este proceso; en cuarto término se habla de la inclusión de posibles nuevos miembros, analizando el caso específico de Taiwán y también la posición de China; en quinto lugar se habla del TPP y el futuro del APEC; y por último se dan unas conclusiones.

Palabras claves: TPP, Perú en el TPP, Taiwán en el TPP, APEC, RCEP.

1 Profesor de la UNMSM. Especialista en Economías Asiáticas. Maestría y Doctorado por la Universidad de Kobe, Japón. E-mail: carloskobe2005@yahoo.com 


\title{
Pensamiento Crítico Vol. 19. N I
}

\begin{abstract}
TPP negotiations are expected to finish this year but this seems to be difficult now. It would be one of the most ambitious liberalizations agreements as it wouldn't leave any sector of the economy out of this process. Furthermore, it is considered that TPP would be a step to complete the process of liberalization between the 21 APEC economies.

In this article the process of liberalization of the TPP is analyzed, starting first with a description of what TPP is; second we will see the points that are in negotiations in the TPP, especially the most contentious ones; third it is seen what Peru can gain from this process; in fourth term it is seen about the possible inclusion of new members, analyzing the specific case of Taiwan and China; fifth what about the TPP and the future of APEC and finally some conclusions are given.
\end{abstract}

Keywords: TPP, Peru and the TPP, Taiwan and the TPP, APEC, RCEP.

\section{1. ¿Que es el TPP?}

El TPP, que son las siglas en ingles del Acuerdo de Asociación Transpacífico, Trans-Pacific Partnership, actualmente agrupa a 12 economías miembros del foro de Cooperación Económica Asia Pacífico, APEC, Asia Pacific Economic Cooperation, que consiste de 21 miembros. El Perú está en el TPP junto con Australia, Brunéi, Canadá, Chile, EE.UU., Japón, Malasia, México, Nueva Zelanda, Singapur y Vietnam. Japón fue el último miembro en ingresar a este grupo, a mediados del año pasado.

El foro APEC reúne, además de los 12 miembros del TPP mencionados, a China. Corea del Sur, Filipinas, Hong Kong, Indonesia, Papúa Nueva Guinea, Tailandia, Taiwán (llamado Taipéi chino) y Rusia. En principio pueden solicitar ser miembros del TPP cualquier integrante del APEC.

El TPP, cuyas negociaciones para establecer una ambiciosa área de libre comercio $e$ inversiones entre sus miembros se espero terminaran en principio a fines del año 2013 aunque no pudo ser así, tuvo sus orígenes en el 2005, cuando cuatro miembros, Brunéi, Chile, Nueva Zelanda y Singapur, establecieron un acuerdo ese año, que entró en efecto el 2006. Conocido originalmente como el bloque P4, estos 4 países 


\section{Carlos Aquino Rodríguez}

alcanzaron un acuerdo para liberalizar sus economías y fue considerado uno de los acuerdos más completos y abiertos en el mundo, pues dejó muy pocos sectores fuera del programa de liberalización. Es interesante notar que eso fue posible pues estos países tenían economías bastante abiertas al mundo, con pocas barreras al comercio y a las inversiones del extranjero. Chile es conocido como un país muy abierto a la competencia extranjera y con bajos aranceles en el continente americano y en Asia ese era el caso de Singapur también.

En el 2008 EE.UU., Australia, Perú y Vietnam, en ese orden, se unieron a las discusiones de este grupo. En el 2010 lo hizo Malasia, en el 2012 México y Canadá, y en el 2013 Japón fue el último. Ese último año anunciaron interés en unirse al grupo Taiwán y Corea del Sur.

Es interesante ver que en el TPP hay economías con distintos niveles de desarrollo. Por un lado están EE.UU., Japón, Australia, con economías desarrolladas, y por otro lado países como Perú y Vietnam, economías en desarrollo. Los primeros tienen un producto bruto interno, PBI (tamaño de su economía), per cápita anual de más de 40 mil dólares, y Perú tiene uno de 6,500 dólares y Vietnam uno de alrededor de 2,000 dólares. Justamente el diferente nivel de desarrollo de los países en el TPP hace que tengan diversos intereses que defender, donde los desarrollados como EE.UU., por ejemplo, quieren una liberalización casi total y especialmente reforzar la protección de la propiedad intelectual de sus empresas, y otros países, como por ejemplo Vietnam, quieren proteger aun algunas de sus empresas que no son competitivas frente a los países desarrollados.

Los 12 miembros del TPP constituyen el 40\% de la economía mundial y el 35\% del comercio mundial. Conforman un mercado de casi 800 millones de habitantes. En 2012 Perú exporto por 14,900 millones de dólares a los 11 países miembros del grupo y esto representó el 32\% del total exportado, e importó de ellos por 13,551 millones de dólares lo que representó también alrededor del 32\% de lo que compramos al mundo entero. Mientras que en el 2013 el Perú exportó a ellos por 14,625 millones de dólares o el 35\% del total y se importó de ellos por 14,579 millones de dólares o el 33\% del total. 


\section{Pensamiento Crítico Vol. 19. No I}

\section{2. ¿Qué negocia el TPP?}

El TPP busca tener un acuerdo muy completo que abarca temas en 29 capítulos, entre los que están: el acceso a mercados, donde se busca eliminar todas las barreras al ingreso de bienes y servicios; reglas de origen, donde se busca por ejemplo que se armonice las disposiciones que definen cuando un producto es originario de un país; las medidas sanitarias y fitosanitarias, que son las disposiciones que los países tienen para el ingreso de productos que tengan que ver con la salud de humanos, animales y plantas; las barreras técnicas al comercio; el tema de la propiedad intelectual; de compras del gobierno; inversiones; servicios financieros; regulaciones ambientales; laboral, comercio transfronterizo de servicios. También ve temas de comercio electrónico; defensa comercial; políticas de competencia; entrada temporal de personas de negocios; facilitación del comercio; desarrollo; coherencia regulatoria; solución de controversias; y pequeñas y medianas empresas. Se busca eliminar las barreras al flujo de bienes, servicios, capital; de uniformizar las disposiciones que los países tienen y que norman el flujo de esos bienes, servicios, y capital. Busca ser el acuerdo más ambicioso y completo, que elimine todas las barreras y no deje excepciones, o sectores sensibles fuera de la liberalización, que usualmente se presenta cuando se firman acuerdos de libre comercio entre los países.

Las negociaciones en el TPP no han terminado pues aún hay puntos contenciosos que resolver. Las negociaciones se iniciaron en el 2010 y hasta diciembre del 2013 se realizaron 19 rondas de negociaciones. En este año 2014, del 22 al 25 de febrero y otra vez el 19 y 20 de mayo, se realizaron en Singapur reuniones de ministros de Comercio y jefes de los equipos negociadores de los países miembros del TPP.

En Lima se realizaron dos rondas, la novena en octubre del 2011 y la décimo séptimo en mayo del 2013.

Algunos de los puntos contenciosos son, por ejemplo, el de la propiedad intelectual, al que EE.UU. pone mucho énfasis en que se apruebe una protección irrestricta, aunque enfrenta la oposición de varios países, entre ellos Malasia. Por ejemplo, EE.UU. quiere que las penas para los que pirateen las películas de Hollywood sean más estrictas, o que los productos farmacéuticos tengan patentes con períodos más extensos de protección, por ejemplo, de 12 años de exclusiva regulación de la data. Se dice que esto podría reducir las oportunidades de mercado para la producción de genéricos a nivel mundial 


\section{Carlos Aquino Rodríguez}

y llevaría a precios altos las medicinas. Otros países, como Chile, han dicho que en el tema de la propiedad intelectual no irán mas allá de las provisiones que sobre esto se dio en el TLC que firmo con EE.UU².

El tema de las empresas públicas y las compras gubernamentales es otro punto contencioso, pues algunos países se oponen a la apertura total de estas a la competencia extranjera. Países como Vietnam, que tienen empresas estatales en varios sectores de la economía, y también Malasia, que por ejemplo privilegia las compras gubernamentales de empresas de miembros de la etnia malaya, la mayoritaria en el país, se verían afectados por eso, y también quiere que se dé un tratamiento especial a las pequeñas y medianas empresas. La forma como se resolverían las disputas entre las empresas extranjeras y el Estado, donde las empresas podrían llevar a los Estados a tribunales internacionales en arbitraje (algo que también quiere EE.UU.) también enfrenta oposición (aunque en otros Tratados de Libre Comercio, TLC, este tema se ha tratado ya, como por ejemplo en el caso del TLC que Perú tiene con Canadá y EE.UU.).

Otro temas son los estándares laborales. Varios países en desarrollo se oponen a que los países desarrollados impongan estándares laborales de sus países en los suyos. Especialmente los sindicatos de EE.UU., como la conocida AFL-CIO (siglas en ingles de la Federación Americana del Trabajo, American Federation of Labor y el Congreso de Organizaciones Industriales, Congress of Industrial Organizations) quieren que los países en desarrollo tengan los mismos estándares laborales que los de EE.UU., para que, dicen, así puedan competir en igualdad de condiciones. Por su parte, algunos países en desarrollo manifiestan que por su diferente nivel de desarrollo no pueden tener todos los mismos estándares. Los sindicatos en EE.UU. por ejemplo se quejan que Vietnam no permite sindicatos independientes y usa mano de obra de niños y de presos en la industria de confecciones ${ }^{3}$.

2 Ver World Trade Online "Incoming Chilean Officials Convey TPP Red Lines In Meeting With Froman". Aquí también se conoció que Chile no está dispuesto a ceder en el tema de la prohibición de los controles de capitales, que busca los EE.UU., pues Chile quiere mantener esta posibilidad para usarlo en el evento de una crisis financiera.

http://insidetrade.com/Inside-US-Trade/Inside-U.S.-Trade-02/14/2014/incoming-chilean-officials-conveytpp-red-lines-in-meeting-with-froman/menu-id-172.html

3 Ver InsideTrade.com "Fact-checking Froman: The Top 10 Myths Used by Obama's Top Trade Official" http://insidetrade.com/iwpfile.html?file=feb2014\%2Fwto2014_0462a.pdf 


\section{Pensamiento Crítico Vol. 19. N I}

Otro aspecto son las regulaciones ambientales. Aquí lo que está en debate es que algunos países, particularmente EE.UU., quieren que las obligaciones ambientales estén sujetas a las mismas disposiciones de solución de controversias como las violaciones comerciales y que las obligaciones que las partes se han comprometido a través de acuerdos multilaterales en asuntos ambientales sean exigibles bajo el TPP. Este punto parece tener la oposición de muchos de los miembros del TPP. Se menciona que en los TLC que ha firmado EE.UU. hay capítulos sobre inversiones donde sus empresas pueden litigar contra los Estados si se sienten amenazadas por una ley ambiental que pueda mermar sus beneficios, y al parecer EE.UU. también quiere que haya esta provisión en el TPP4

En el tema de reglas de origen está la discusión respecto a los textiles, por ejemplo. Vietnam quiere que se continúe usando telas de fuera de los países miembros del TPP y aún así que la ropa hecha con esa tela pueda entrar al mercado de EE.UU. gozando de preferencias arancelarias. Pero EE.UU. se opone a esto y quiere que la tela o el hilo usado en la producción de esa ropa vengan de un país miembro del TPP. Lo que pasa es que Vietnam usa tela de Taiwán, que no es miembro del TPP. $82 \%$ de la ropa que importa EE.UU. de países miembros del TPP viene de Vietnam, 9\% del Perú, y 6\% de Malasia.

En temas de acceso a los mercados, está la discusión de cómo los países ofrecen reducir o eliminar sus aranceles a los productos importados. Es el caso por ejemplo de Japón, que quiere mantener algunos sectores de su agricultura y ganadería cerrados a la competencia extranjera (como se verá más adelante).

En el caso del Perú, su posición en las negociaciones en el TPP es, según declaraciones de la ministra del Mincetur, que no se irá en las concesiones más allá de lo que se negocio en el TLC con EE.UU., y que el Perú tiene interés en "tener más acceso a mercados y flexibilización sanitaria" 5 .

Uno de los aspectos que se dice caracteriza las negociaciones del TPP, y que suscita críticas, es la forma aparentemente secreta en que muchas de sus negociaciones se llevan a cabo.

4 Ver tambien InsideTrade.com "Fact-checking Froman: The Top 10 Myths Used by Obama's Top Trade Official", pagina 6.

http://insidetrade.com/iwpfile.html?file=feb2014\%2Fwto2014_0462a.pdf

5 Según declaraciones de la Ministra publicada en el diario Gestión, 21 de febrero del 2014, pagina 14 "Mincetur: Los gremios conocen lo que se negocia en el TPP" 


\section{Carlos Aquino Rodríguez}

Un tema adicional, y que puede crear retrasos en el término de las negociaciones, es que EE.UU., que es el principal impulsor del TPP, está teniendo problemas para que el Gobierno obtenga la llamada "vía rápida" o "fast track", que le daría la ley o Autoridad de Promoción Comercial, TPA por sus siglas en ingles Trade Promotion Act, para aprobar rápidamente el TPP en el Congreso. El TPA, que hace que el Congreso del país apruebe o rechace un tratado comercial tal como está, sin hacer modificaciones, venció en el 2007 y no ha sido extendido, a pesar de que el Gobierno trata de que sea así. Últimas declaraciones de líderes del Congreso de EE.UU. apuntan a que no ven una urgencia en tener esta "vía rápida", lo que se dice podría restar ímpetu al Gobierno de EE.UU. para lograr terminar pronto las negociaciones del $\mathrm{TPP}^{6}$. Se teme que la aprobación del TPA se dé en el Congreso después de las elecciones de mitad de término de noviembre de este año en EE.UU.

La oposición actual del Congreso de EE.UU. a otorgar la "vía rápida" para la aprobación de un acuerdo en el TPP en el Congreso se debe a que hay temor de los sindicatos y otros grupos de que este acuerdo pueda hacer perder puestos de trabajo en EE.UU. y hacer que sus empresas se vayan a producir fuera del país, como algunos critican sucedió con el Acuerdo de Libre Comercio de América del Norte, NAFTA, o North America Free Trade Agreement, entre Canadá, EE.UU. y México, ahora que se celebran 20 años de este acuerdo. También se critica lo poco transparente que son las negociaciones en el TPP, y que se establezcan reglas de propiedad intelectual que pongan restricciones al acceso de medicina genéricas en los países en desarrollo. Asimismo se critica que el TPP pueda fijar estándares no muy altos, o los mecanismos para hacerlos cumplir, en la protección del medio ambiente y en los derechos laborales ${ }^{7}$.

Del 22 al 25 de febrero y otra vez del 19 al 20 de mayo se realizaron reuniones de ministros de Comercio y jefes de equipos negociadores de los países miembros del TPP en Singapur. En estas reuniones no se llegó a finalizar las negociaciones como algunos hubieran querido. De hecho, en uno de los puntos más importantes en el tema

6 Ver Nikkei Asian Review "America's TPP debacle leaves Hamlet without the prince" http://asia.nikkei.com/magazine/20140213-SAMSUNG-ON-STORM-WATCH/Politics-Economy/Americas-TPP-debacle-leaves-Hamlet-without-the-prince

7 Ver Los Angeles Times "The Trans-Pacific Partnership: Who wins, who loses, why it matters" http://www.latimes.com/nation/politics/politicsnow/la-pn-trans-pacific-partnership-20140219,0,6747764. story\#axzz2u61PEfBe 


\section{Pensamiento Crítico Vol. 19. N I}

de acceso a mercados, la discusión ente Japón y EE.UU. por la mayor apertura del mercado japonés agropecuario, no se llegó a alcanzar un acuerdo. Según el ministro japonés presente en la reunión de febrero, "aún quedan considerables brechas entre los dos países". Al parecer se requiere una decisión política para destrabar este tema entre ambos lados, algo que se supone pudo ocurrir en la visita que el presidente Barack Obama hizo a Japón en abril, pero como se verá esto parece no fue así tampoco.

Por otro lado, en la reunión de febrero, según el Ministro de Comercio de Malasia, se alcanzó un acuerdo en 8 temas o capítulos. Estos serían: en el de desarrollo; coherencia en las regulaciones; competitividad y facilitación de los negocios; pequeñas y medianas empresas; entrada temporal; cooperación y construcción de capacidades; acuerdos institucionales y administrativos; y parte del capítulo de la política de competencia no relacionado con las empresas del Estado ${ }^{9}$, los mismos que el mismo ministro había anunciado el primer día de las reuniones ${ }^{10}$.

Se alcanzó un acuerdo en una parte del tema de las empresas públicas. Se acordó que los "Gobiernos puedan seguir proveyendo apoyo a sus empresas estatales cuando estas ofrezcan servicios en el mercado domestico" 11 . Se acordó que las disciplinas del TPP se aplicaran a las empresas públicas cuando estas ofrezcan bienes en sus países o cuando ofrezcan servicios en otros países miembros del TPP o terceros países. Esos servicios exceptuados en el mercado interno son servicios financieros, telecomunicaciones, salud, educación, servicios express de correo y servicios de distribución.

La reunión terminó con una declaración de los ministros, donde dicen que han avanzado en algunos temas, sin especificarlos, y que seguirán haciendo esfuerzos para

8 Ver Japan Today: "Japan, U.S. fail to make headway in TPP talks http://www.japantoday.com/category/politics/view/japan-u-s-fail-to-make-headway-in-tpp-talks

9 Ver Insidetrade.com "Malaysia Flags Major TPP Outstanding Issues, Says U.S. Needs TPA To Conclude" http://insidetrade.com/201402212461982/WTO-Daily-News/Daily-News/malaysia-flags-major-tppoutstanding-issues-says-us-needs-tpa-to-conclude/menu-id-948.html

10 Al término del primer día de reuniones el Ministro de Comercio de Malasia dijo que se habían puesto de acuerdo en solo 8 de los 29 capítulos, y que esos no eran los más controversiales ni los más importantes. Ver Japan Today "Trade ministers resume TPP talks in Singapore" http://www.japantoday.com/category/ politics/view/trade-ministers-resume-tpp-talks-in-singapore

11 Ver World Trade Online "U.S., Other TPP Countries Agree To Narrow Scope Of SOE Chapter" http://insidetrade.com/201402252462235/WTO-Daily-News/Daily-News/us-other-tpp-countries-agree-tonarrow-scope-of-soe-chapter/menu-id-948.html 


\section{Carlos Aquino Rodríguez}

tener un acuerdo en todos los demás restantes ${ }^{12}$. En la reunión de mayo tampoco se alcanzó un acuerdo final y los ministros acordaron seguir discutiendo los temas ${ }^{13}$.

\section{3. ¿Cómo el Perú se podría beneficiar del TPP?}

Si bien el Perú ya tiene TLC con algunos miembros del TPP, como con Canadá, Chile, EE.UU., Japón, México y Singapur, el estar en el TPP con esos países le permitiría obtener mayores beneficios que con los TLC bilaterales que tiene con cada uno de ellos. Por ejemplo, en el TLC que Perú tiene con Japón (llamado Acuerdo de Asociación Económica), este país exceptuó de la apertura de su mercado al Perú muchos productos de su sector agropecuario. En el TPP, Japón se ha comprometido a liberalizar casi la totalidad de su sector agropecuario, excepto cinco categorías de productos que consideran que no podrían abrir, los cuales son carne de vacuno y de cerdo, arroz, azúcar, trigo y cebada, y productos lácteos, aunque incluso esto está en discusión en las negociaciones en el TPP para ver si algún o algunos de esos productos pueden ser abiertos a la competencia extranjera. Japón quiere seguir protegiendo unos 586 ítems bajo esas 5 categorías pero EE.UU., por ejemplo, es uno de los que quiere que no haya protección a ninguno de ellos o en todo caso se reduzca esta lista, y justamente estos dos países están negociando eso, pero al parecer no alcanzan un acuerdo aún ${ }^{14}$. Como referencia, en el TLC de Perú con Japón, este país excluyó 749 líneas arancelarias ${ }^{15}$.

Japón protege esos sectores con altos aranceles o aranceles tipo cuota. Por ejemplo, para la carne de vacuno tiene una arancel de $38.5 \%$, para queso natural un $29.8 \%$. Para el arroz tiene una tarifa tipo cuota, donde permite una importación anual de 787 mil toneladas métricas al año (del cual casi la mitad viene de EE.UU.), donde estas importaciones no pagan arancel pero arriba de esa cuota pagan un arancel altísimo que prácticamente no se importa más allá de ese monto. Aun así, Japón importa un gran

12 Ver World Trade Online: "TPP Ministers Announce Agreement On Majority Of Landing Zones, Say Work Remains For Market Access"

http://insidetrade.com/201402252462236/WTO-Documents/Text-Document/tpp-ministers-announceagreement-on-majority-of-landing-zones-say-work-remains-for-market-access/menu-id-174.html

13 ICTSD: "Ministers Pledge to Intensify TPP Talks at Singapore Meet":

http://www.ictsd.org/bridges-news/bridges/news/ministers-pledge-to-intensify-tpp-talks-at-singapore-meet

14 Ver Nikkei Asian Review: "Japan, U.S. still slogging on in TPP talks".

http://asia.nikkei.com/Politics-Economy/International-Relations/Japan-U.S.-still-slogging-on-in-TPP-talks

15 Ver agraria.pe: "Tras TLC Perú Japón. Destacan el café y espárragos

99,8\% DE PRODUCTOS CON ACCESO PREFERENCIAL A JAPÓN"

http://www.agraria.pe/noticias/998-de-productos-con-acceso-preferencial-japon 


\section{Pensamiento Crítico Vol. 19. N I}

monto de esos productos que protege, por ejemplo el $60 \%$ de la carne de vacuno que consume, la tercera parte de los productos lácteos que consume, el $90 \%$ del trigo que consume (del cual EE.UU. suple el $60 \%$ de sus importaciones), etc. ${ }^{16}$

Lo que al parecer va a definir cuántos de los productos que Japón aún protege de esas categorías sean dejadas de lado serán las negociaciones que el país oriental tiene con EE.UU. Japón se dice estaría dispuesto a permitir más importaciones en algunas de esas categorías si EE.UU., por su lado, deja de poner aranceles de $2.5 \%$ que aún mantiene contra los automóviles japoneses y especialmente el arancel de $25 \%$ que tiene contra camiones ligeros japoneses ${ }^{17}$.

Al final, parece que Japón dejaría de proteger algunos productos de esos 5 sectores, pues según un informe, en el año fiscal 2010 al parecer un $40 \%$ de esos productos protegidos no fueron importados ese año, lo que significa que no habría demanda y por tanto necesidad de ponerle barreras a su ingreso ${ }^{18}$. El tema del arroz es el más sensible para Japón, así que en este producto se ofrecerá más resistencia, aunque en verdad su protección radical no va de acuerdo a la posición cambiante de este producto en la dieta japonesa ni en la agricultura japonesa. De acuerdo a un estudio, el valor de la agricultura japonesa declinó un tercio de 1984 al 2011, los ingresos del sector agrícola cayeron a la mitad de 1990 al 2007, en 1960 el arroz representaba la mitad del valor de la producción agrícola, en el 2000 su participación cayó por debajo del $20 \%$, sus agricultores son cada vez personas de mayor edad, y solo en el 2010 unas 400 mil hectáreas dejaron de producirse o fueron abandonadas, por el envejecimiento de los agricultores o por lo poco rentable que es la agricultura. El arroz tiene un arancel de casi $800 \%$ en Japón ${ }^{19}$.

16 Ver World Trade Online: "Beef, Pork, Dairy Are Likely Sticking Points In U.S.-Japan Agriculture Talks" http://insidetrade.com/201402242462158/WTO-Daily-News/Daily-News/beef-pork-dairy-are-likelysticking-points-in-us-japan-agriculture-talks/menu-id-948.html

17 See Japan Times "Concessions on farm products eyed as advance TPP talks with U.S. begin" http://www.japantimes.co.jp/news/2014/02/18/business/amari-hints-japan-may-make-concessions-overfarm-products-tariffs/\#.UwNpzGJ5MhM

18 Ver Global Post " $40 \%$ of TPP sensitive farm goods never imported into Japan in FY 2010" http://www.globalpost.com/dispatch/news/kyodo-news-international/131218/40-tpp-sensitive-farmgoods-never-imported-japan-fy-20

19 Ver Forbes "TPP Or No TPP Japanese Agriculture Must Be Reformed" http://www.forbes.com/sites/stephenharner/2013/08/19/tpp-or-no-tpp-japanese-agriculture-must-bereformed/ 


\section{Carlos Aquino Rodríguez}

Es interesante anotar que varios países en el TPP miran atentamente las negociaciones entre EE.UU. y Japón para que el país oriental abra su mercado en el sector agropecuario, pues de eso dependerá lo que ellos también pidan a Japón y a EE.UU.: abrir más sus mercados. Por ejemplo, Australia y Nueva Zelanda, que son competitivos en productos lácteos y enfrentan algunas barreras en EE.UU. para vender estos productos, esperan que si Japón abre su mercado a EE.UU. a los productos lácteos por ejemplo, también EE.UU. haga lo mismo en su mercado. En el TLC que EE.UU. firmó con Australia, EE.UU. no liberalizó totalmente su mercado de productos lácteos ante el temor de la mayor competencia de Australia ${ }^{20}$.

Pero Japón y Australia recientemente firmaron un Acuerdo de Asociación Económica. En este, "Australia eliminará el arancel de 5\% a los productos electrónicos japoneses inmediatamente y el arancel de 5\% a los autos se terminará en 5 años". Para Australia, "habrá significativas reducciones en el arancel japonés a la carne, el arancel de $38.5 \%$ a la carne congelada se rebajará a $19.5 \%$ en 15 años, y un arancel similar a la carne fresca y refrigerada se reducirá a $23.5 \%$ en el mismo período". También "los exportadores de queso de Australia tendrán arancel cero al queso cheddar, que podrá aumentar a unas 27 mil toneladas métricas en un lapso de 20 años, con otras concesiones para los productos de la horticultura, productos de mar, azúcar y vino" 21 .

En todo caso, además de lo anterior, el Perú ganaría acceso a mercados de países con los cuales no tiene actualmente TLC pero que están en el TPP, como son Australia, Brunéi, Malasia, Nueva Zelanda y Vietnam. Australia es un mercado con 23.5 millones de habitantes, consumidores con un ingreso per cápita de más de 65 mil dólares, mientras que Vietnam, aunque sus habitantes tienen un PBI per cápita de solo 2,000 dólares, estos son 90 millones y es un país que crece a tasas muy altas en Asia.

Por ejemplo, el Perú exporta pescado y mariscos a varios países pero Vietnam tiene aranceles en estos rubros hasta de un 35\%. Podría exportar madera y productos relacionados pero Vietnam tiene un arancel de 31\% y Malasia uno de $40 \%$ en estos productos $^{22}$.

20 Ver Insidetrade.com "japan's market access offer, if accepted by the U.S., Would be a radical departure from past U.S. Trade policy and create a horrible precedent"

http://insidetrade.com/iwpfile.html?file=feb2014\%2Fwto_02222014_b.pdf

21 See The Diplomat: "Australia and Japan Conclude Free Trade Deal"

http://thediplomat.com/2014/04/australia-and-japan-conclude-free-trade-deal/

22 Ver Foreign Affairs, Trade and Development Canada "Benefits Across Canada of a Trans-Pacific Partnership Agreement"

http://www.international.gc.ca/trade-agreements-accords-commerciaux/agr-acc/tpp-ptp/benefits- 


\section{Pensamiento Crítico Vol. 19. N I}

\section{Posibles nuevos miembros en el TPP y el caso específico de Taiwán y China}

En esta parte, veamos brevemente primero un resumen del desarrollo económico de Taiwán, y segundo cómo sería el proceso de adhesión de Taiwán al TPP y los temas que esto implicaría, así como las ventajas de su admisión a este acuerdo. También veremos cómo China ve una posible participación en el TPP.

\subsection{Desarrollo económico de Taiwán}

Taiwán es uno de los casos exitosos de rápido desarrollo en el Asia Oriental. Considerado uno de los 4 tigres, junto con Corea del Sur, Hong-Kong y Singapur, pasó de tener una economía mayoritariamente agrícola en la década de 1950 a convertirse en una industrializada en los años 1980. Su ingreso per cápita pasó de 213 dólares en 1952, a 2,835 dólares en 1980 y en el 2012 alcanzó un nivel de 20,386 dólares ${ }^{23}$. El tamaño de su economía pasó de 1,711 millones de dólares en el año 1952 a 474,269 millones de dólares en el 2012 (todos los datos económicos que se mencionen en esta parte, a menos que se indique lo contrario, son del "Taiwán Statistiscal Data Book 2013" publicado por el Council for Economic and Planning Development, CEPD, de Taiwán).

Taiwán es un isla que tiene solo 36 mil kilómetros cuadrados de extensión, y su población a fines del 2012 era de 23.3 millones de habitantes. No tiene mayores recursos naturales, excepto terreno agrícola para cultivos tropicales especialmente, y es totalmente dependiente de la importación de recursos mineros y energéticos.

Lo más espectacular de Taiwán, y que hace en ese sentido que su desarrollo económico sea encomiable, es que ese rápido desarrollo ha sido alcanzado con una distribución del ingreso que es la más igualitaria en mundo. Esto es, los frutos del crecimiento económico se han distribuido más equitativamente que en otros países. El índice Gini, que mide este, fue de 0.342 en el 2012 (mientras que en China y Perú por

avantages.aspx?lang=eng

23 "Taiwán Statistiscal Data Book 2013" del CEPD, Taiwán, página 19. Para una mayor descripción del desarrollo económico de Taiwán ver el capitulo IX de mi libro: "Introducción a la economía asiática", año 2000, UNMSM, que se puede obtener de internet en el sitio:

http://economia.unmsm.edu.pe/Servicios/Publicaciones/Libros/Libro2.htm 


\section{Carlos Aquino Rodríguez}

ejemplo, este índice está en alrededor de 0.45 a 0.48$)^{24}$. Su tasa de desempleo fue de $4.24 \%$ en el 2012, y en las décadas de 1970 a 1990 esa tasa estuvo alrededor de $2 \%$ e incluso menos.

El desarrollo económico de Taiwán ha sido impulsado en gran parte por las exportaciones. Estas pasaron de 116 millones de dólares en 1952 a 19,811 millones de dólares en 1980 y a 301,101 millones de dólares en el 2012 (y fueron de 308,257 millones de dólares en el 2011). Todo esto le ha permitido acumular reservas internacionales en su Banco Central, a fines del 2012, por un valor de 403,169 millones de dólares.

Taiwán pudo desarrollarse, y lo hizo en forma equitativa, pues tomó una serie de medidas que pasaron por una reforma agraria y desarrollo del campo, un proceso de industrialización que pasó por una industria intensiva en mano de obra primero, luego una intensiva en capital y, por último, una industria intensiva en tecnología y conocimientos, y un sistema educativo que le permitió tener una mano de obra educada. El Gobierno implementó Planes quinquenales de desarrollo económico, y dio facilidades a sus empresas para que puedan alcanzar las metas de crecimiento económico y exportaciones.

Uno de los casos más exitosos de cómo se promovió una industria fue el establecimiento de parques industriales de ciencia y tecnología. En 1980 se crea el Parque Industrial de Ciencia y Tecnología de Hinschu, lo que ha permitido que Taiwán se convierta hoy en líder mundial en varias de las industrias de tecnología de la información y la comunicación (ver más adelante sobre esto).

En 2012 los gastos en investigación y desarrollo fueron de 3.02\% del PBI, uno de los más altos en el mundo (en el Perú ese gasto es de alrededor de $0.15 \%$ del PBI). Tiene una mano de obra muy educada, en el 2012 casi el 40\% de su población (exactamente $39.45 \%$ ) tenía educación superior (en el año 1974 este nivel era de solo 6.47\%).

En el 2012 Taiwán estaba en el 13er lugar como el más competitivo en el mundo, de acuerdo a cifras del World Economic Forum, WEF, y de acuerdo al International Institute for Management Development, IMD, estaba en el 11er lugar en el año 2013.

24 El índice Gini varía de 0 a 1 , donde 0 indica absoluta igualdad y 1 significa absoluta desigualdad. Mientras menor el índice, un país es más igualitario. 


\section{Pensamiento Crítico Vol. I9. No I}

\subsection{Sobre la posible admisión de Taiwán al TPP}

En principio se ha dicho que el TPP está abierto a los demás miembros del foro APEC. Así, como se indicó Taiwán y Corea del Sur han manifestado interés en participar en las negociaciones del TPP. Ambas son economías miembros del APEC, y tienen ya TLC con algunos de los que están en el TPP.

En el caso de Corea, este país ya inició consultas con algunos miembros del TPP en enero de este año, con Chile, EE.UU., Malasia, México, Perú, Singapur, sobre su posible participación y parece que estos países le han manifestado su simpatía para que ingrese al TPP, al mismo tiempo que buscan asegurar que Corea cumpla con los estándares de alta calidad de este acuerdo. En febrero continuó consultando con los 6 países restantes del TPP sobre su posible ingreso. Una decisión del Gobierno coreano para solicitar formalmente su ingreso al parecer se esperaba para fines de marzo, cuando un instituto de investigación que recibe fondos del Gobierno terminara un estudio sobre las implicancias de la participación de Corea en el TPP.

Corea ya tiene acuerdos comerciales o TLC con varios países del TPP, como con EE.UU., Chile, Perú, entre otros.

En el caso de Taiwán, este tiene acuerdos de libre comercio con Singapur y Nueva Zelanda, dos miembros del TPP.

Es interesante notar, por ejemplo, que Corea del Sur ocupa el cuarto lugar como potencia comercial en el foro APEC y si ingresa al TPP sería el tercero mayor en este grupo. En el caso de Taiwán, este ocupa el décimo lugar como potencia comercial en el foro APEC y si ingresa al TPP sería el sexto mayor aquí.

Considerando con más detalle el caso especifico de Taiwán y su posible ingreso al TPP, hay varios elementos para tomar en cuenta, como su relación con los demás miembros del TPP y con China en particular, dada la particular situación de Taiwán, un importante actor en la economía y comercio mundial, pero que no participa en la mayoría de los organismos internacionales por no ser considerado un Estado soberano por la mayoría de países. 


\section{Carlos Aquino Rodríguez}

Hay que notar que Taiwán tiene con China un Acuerdo Marco de Cooperación Económica, llamado ECFA por sus siglas en inglés Economic Cooperation Framework Agreement. Es un tipo de TLC vigente entre ellos desde el 2010, y que ha impulsado grandemente las relaciones económicas entre ambos. Cubre no solo el comercio de bienes sino una serie de sectores más, como banca y seguros. Para Taiwán actualmente China es su mayor socio comercial y el mayor destino para sus inversiones. El año pasado el intercambio comercial entre China y Taiwán fue de más de 180 mil millones de dólares y un monto quizás similar a ese es el que las empresas taiwanesas tienen invertido en China hasta el año pasado (según estadísticas oficiales de Taiwán de 1991 al 2012 había un total acumulado de 124 mil millones de dólares de inversión aprobada en China, y solo el año 2012 ese monto fue de 12.7 mil millones de dólares ${ }^{25}$ ).

En el 2012 el 26.8\% de las exportaciones de Taiwán fueron a China, y a EE.UU., que ocupó el segundo lugar, fue el 10.9\% del total. Por el lado de las importaciones, ese año vinieron de Japón el $17.6 \%$ y de China el $15.1 \%$ del total.

Además, los turistas chinos son la mayor parte de los turistas que visitan Taiwán, y el año 2013 unos 2.87 millones de ellos visitaron esta isla, el 36\% de un total de 8 millones. Por su parte 3.07 millones de taiwaneses visitaron China el año pasado ${ }^{26}$.

Es interesante ver cómo las relaciones de China con Taiwán han avanzado, al punto que, por ejemplo, se puede cambiar más fácilmente moneda china por dólares en Taiwán que en la propia China. Este autor lo pudo comprobar el año pasado, cuando en marzo asistió invitado al 5to Foro Mundial de Estudios sobre China en Shanghái. Al final de mi estadía en China tenía moneda china, yuanes, por más de 500 dólares en el bolsillo, así que quise cambiar todo por dólares, pero no sabía que hay una regulación en China que estipula que un extranjero solo puede cambiar yuanes a dólares hasta por un monto de 500 dólares al día. Como era mi último día en China solo pude cambiar mis yuanes hasta por ese monto de 500 dólares, pero tenía que ir a Taiwán después invitado a otro Congreso, en Taipéi, y descubrí que en Taiwán no hay prácticamente límites para cambiar moneda china por dólares.

25 Ver "Taiwán Statistiscal Data Book 2013" del CEPD, Taiwán, página 266

26 See FOCUS Taiwan "China largest source of visitors to Taiwan in 2013: MOTC" http://focustaiwan.tw/news/asoc/201402070018.aspx 


\section{Pensamiento Crítico Vol. 19. N I}

Para ingresar al TPP, que busca comó se indico liberalizar o eliminar casi todas las barreras al flujo de bienes, servicios y capital, Taiwán tendrá que hacer algunas reformas en su economía y reducir las barreras que aún tiene al comercio con otros países. Por ejemplo, tiene aún barreras o cuotas para el ingreso del arroz extranjero, y está también en un tira y afloja con EE.UU. para permitir el ingreso de carne de cerdo de EE.UU. tratado con ractopamina, fármaco que se usa como aditivo alimenticio para promover el crecimiento de esos animales, que Taiwán prohíbe, como muchos otros países, pero que EE.UU. permite y quiere que también Taiwán lo haga ${ }^{27}$.

Taiwán podría perder si no entra en el TPP pues, por ejemplo este acuerdo trata de establecer reglas de origen (que determinan el porcentaje de contenido o de origen de un producto de un lugar determinado para que pueda ser importado gozando de beneficios por el otro país miembro del acuerdo). En el caso de textiles o ropa, por ejemplo EE.UU. pedirá que un porcentaje del valor agregado de esos productos que importe sea hecho con hilos de EE.UU. o de otros países miembros del acuerdo, restringiendo el uso de hilos que provengan de países que no son miembros del TPP. Vietnam, que es uno de los más grandes exportadores de textiles y ropa a EE.UU., usa bastante hilo de Taiwán en sus prendas que exporta a EE.UU. y de establecerse esa regla, Vietnam dejaría de comprar hilo de Taiwán.

Lo anterior muestra cuán importante son las cadenas globales de valor en Asia y cómo especialmente Taiwán está involucrado en esto. Las cadenas globales de valor o cadenas de suministro globales involucran a muchos países en la producción de un bien, con algunos proporcionando partes y componentes que son procesados en otros países y finalmente ensamblados en un bien final en otro país. Las industrias de automóviles, productos electrónicos, textiles y ropa están muy involucradas en esto. Un ejemplo también es la fabricación del iPad, que se ensambla en China, con partes y componentes que provienen de diversos lugares, entre ellos muchos de Asia, incluido Taiwán, y es ensamblado justamente por una empresa taiwanesa, Foxconn ${ }^{28}$.

27 Ver the brookings institution center for east asia policy studies "taiwan and the trans-pacific partnership: preparing the way"

http://www.brookings.edu/ /media/research/files/papers/2013/10/taiwan\%20transpacific\%20 partnership\%20bush\%20meltzer/taiwan\%20and\%20tpp\%20bush\%20and\%20meltzer\%20103013.pdf

28 Ver sobre esto un artículo que publique en la revista Pensamiento Crítico, de la Facultad de Ciencias Económicas de la Universidad Nacional Mayor de San Marcos, Vol. 18, No. 1, junio 2013, págs. 7 al 42 "El rol de China en la economía asiática e implicancias para la economía mundial" 


\section{Carlos Aquino Rodríguez}

Taiwán tiene competidores como Corea del Sur y Singapur en industrias de productos electrónicos, cierto tipo de maquinaria, productos de las industrias de tecnologías de información y comunicación, y estos dos países tienen diversos tratados de libre comercio que permiten que sus productos ingresen con acceso preferencial, mientras que Taiwán está limitado en esto. Por eso es importante que Taiwán ingrese al TPP, para no perder competitividad con esos países.

Se dice que para que Taiwán entre al TPP, en cierta forma China tendría que ingresar también, pues esto ha sido así en otros organismos, como en el foro APEC, donde en 1993 ingresaron juntos China, Hong Kong y Taiwán.

Habría que señalar que en los últimos años las relaciones entre Taiwán y China no solo han mejorado en términos económicos como se vio, sino que incluso en el tema político también. Una muestra de ello es la reunión que sostuvieron a comienzos de febrero el jefe de la Oficina de Asuntos de Taiwán, de China, y el jefe de la Oficina de Asuntos del Continente, de Taiwán. Es la primera vez, se dice, que altos funcionarios de ambos lados del Estrecho de Taiwán se reúnen, desde 1949, cuando termino la guerra civil en el continente donde el Partido Comunista ganó la guerra al Partido Nacionalista o Kuomintang, y este se retiró a Taiwán, donde constituyó un Gobierno aparte. Desde ese año, ambos lados del Estrecho están separados ${ }^{29}$.

En el proceso de adhesión al TPP, Taiwán tendría que ganar el consentimiento de los demás miembros y en esta circunstancia el apoyo de EE.UU. será vital. Se dice que para que esto sea así, Taiwán tendrá que terminar un acuerdo de inversión con EE.UU. dentro de las conversaciones entre las dos partes para un Acuerdo Marco de Comercio e Inversiones, o TIFA por sus siglas en inglés, Trade and Investment Framework Agreement ${ }^{30}$. Usualmente un acuerdo sobre inversiones precede a un Acuerdo de Libre Comercio entre dos países, por eso la importancia que Taiwán alcance ese acuerdo con EE.UU.

Taiwán comercia actualmente casi un $30 \%$ del total con los miembros del TPP. El año 2012 un $30 \%$ de sus exportaciones fueron a los 12 miembros del TPP y un $28 \%$

29 Ver BBC News "China and Taiwan in first government talks" http://www.bbc.co.uk/news/world-asiachina-26129171

30 Ver Want China Times "Taiwan to seek US support for TPP bid at TIFA talks"

http://www.wantchinatimes.com/news-subclass-cnt.aspx?id=20140218000099\&cid=1201 


\section{Pensamiento Crítico Vol. 19. N I}

de sus importaciones vinieron de esos países ${ }^{31}$. De ingresar al TPP podría aumentar sus negocios con estos socios comerciales. Ahora, con China comercia casi un $23 \%$ del total (y si añadimos Hong Kong casi el $40 \%$ de las exportaciones de Taiwán van a China y Hong Kong) y este comercio aumenta desde que Taiwán hizo el acuerdo ECFA con China y Taiwán necesita no ser tan dependiente de este país y esto lo lograría con su ingreso al TPP.

Taiwán también tiene interés en negociar el TPP pues es casi el único en el Asia Oriental que no está presente en el gran esquema de integración económica que se quiere formar en esa región, la Asociación Económica Regional Global, llamado RCEP por sus siglas en ingles, Regional Comprenhensive Economic Partnership (ver más adelante sobre esto). Se calcula que un $57 \%$ del comercio de Taiwán se realiza con los miembros del RCEP ${ }^{32}$.

Debido al estatus especial que Taiwán tiene, de no ser reconocido como un estado soberano por la mayoría de los países, ha sido excluido de la mayoría de acuerdos comerciales en la región. Pero al participar en el foro APEC y ser una potencia comercial importante, pues fue el 18avo exportador e importador más grande del mundo en el 2012, con 301 mil millones de dólares y 270 mil millones de dólares, respectivamente ${ }^{33}$, sería un socio importante para el resto de los miembros del TPP. Entrando al TPP, le sería más fácil también a Taiwán ingresar al RCEP ${ }^{34}$.

Taiwán ha participado activamente en el foro APEC y ha hecho importantes contribuciones. Por ejemplo, tiene un proyecto para cerrar la brecha digital que hay entre los miembros del APEC. Propuso en la Reunión de Líderes del APEC el 2003 en Bangkok cerrar la brecha digital que se hacía más grande entre los miembros por la explosión en la infraestructura de las tecnologías de la información y comunicaciones. Taiwán contribuyó al financiamiento del APEC Digital Opportunity Center, ADOC, para cerrar esa brecha, convirtiéndola en una oportunidad digital. Como lugar donde se produce la mayoría de las partes, componentes y productos finales de la industria

31 De acuerdo a estadísticas del "Taiwán Statistiscal Data Book 2013" del CEPD, Taiwán

32 Ver Noticias, Boletin Informativo sobre Taiwan "Reafirman el deseo de Taiwan por ingresar a dos bloques regionales". Aquí se afirma que el comercio de Taiwán con los miembros del TPP representan el 34.3\% del total. http://noticias.nat.gov.tw/ct.asp?xItem $=214792 \& \mathrm{ctNode}=1718 \& \mathrm{mp}=12$

33 Ver cuadro I.7, pagina 24, del International Trade Statistics 2013, de la OMC.

34 Roy Chun Lee: "The importance of TPP for Taiwan"

http://iis-db.stanford.edu/evnts/7924/Lee.Taiwan\%E2\%80\%99s_View_of_the_TPP.pdf 


\section{Carlos Aquino Rodríguez}

informática en el mundo, Taiwán estaba bien posicionado para esto (ver cuadros 1 y 2 ). Iniciado en el 2004, después de 10 años de exitosa implementación, su continuación enfrenta nuevos desafíos, uno de ellos el financiamiento ${ }^{35}$.

Los cuadros 1 y 2 muestran como Taiwán es el más competitivo en el mundo en muchos de los productos de las industrias de la tecnología de la información y la comunicación, y justamente es en esos sectores donde los países pueden beneficiarse al tener un acuerdo comercial con Taiwán. Por ejemplo, en computadoras notebook and netbook Taiwán tenía en el 2012 una participación de 89\% de la producción mundial, en las tabletas personales tenía un $87.8 \%$, en monitores LCD un $67.8 \%$, por mencionar alguno de ellos.

De ser admitido Taiwán al TPP, los demás miembros gozarían de un mejor acceso a esos productos y podría pensarse en atraer también mayor inversión de Taiwán a sus países.

\section{Cuadro 1: Productos en los que Taiwán estaba entre los tres más grandes productores en el mundo en el 2012, incluyendo producción en el extranjero}

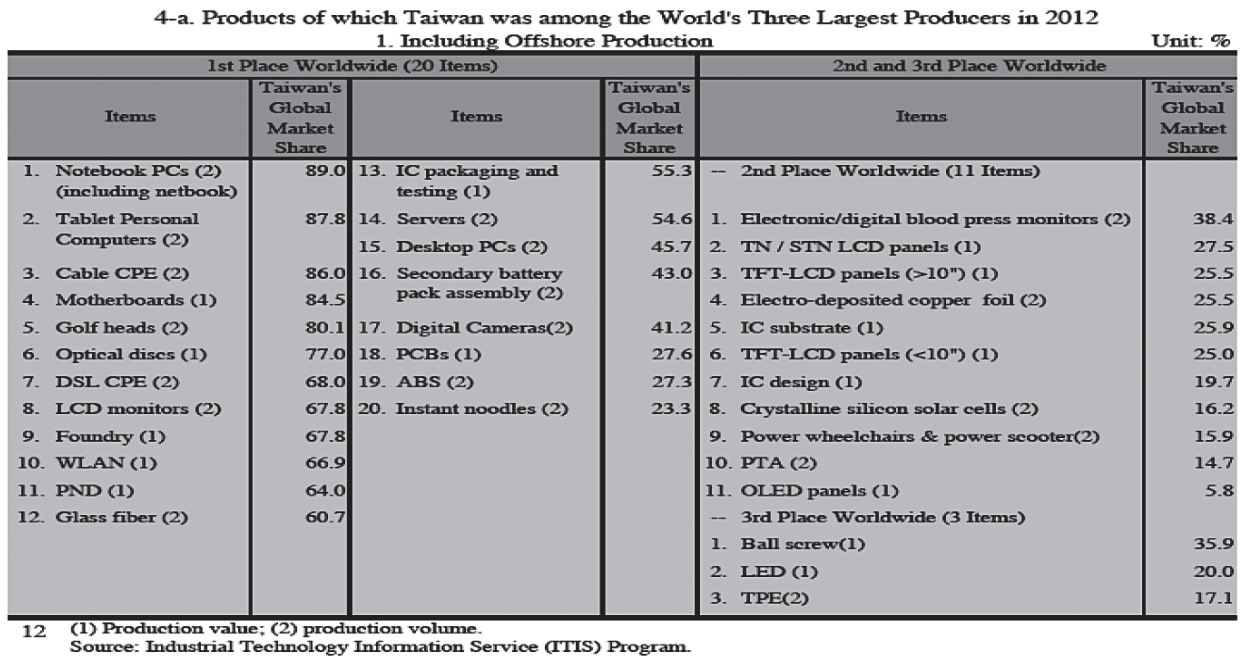

Fuente: "Taiwán Statistiscal Data Book 2013" del CEPD, Taiwán, página 12

35 Ver Taiwan Focus "Bridging the Digital Divide 1: Taiwan project faces unknown future http://focustaiwan. tw/news/aeco/201401010027.aspx 


\section{Pensamiento Crítico Vol. 19. N I}

\section{Cuadro 2: Productos en los que Taiwán estaba entre los tres más grandes productores en el mundo en el 2012, excluyendo producción en el extranjero}

4-b. Products of which Taiwan was among the World's Three Largest Producers in 2012

2. Excluding Offshore Production

\begin{tabular}{|c|c|c|c|c|c|}
\hline \multicolumn{2}{|c|}{ lst Place Worldwide (5 Items) } & \multicolumn{2}{|l|}{ 2nd Place Worldwide (11 Items) } & \multicolumn{2}{|c|}{ 3rd Place Worldwide (8 Items) } \\
\hline Items & $\begin{array}{c}\text { Taiwan's } \\
\text { Global } \\
\text { Market } \\
\text { Share } \\
\end{array}$ & Items & $\begin{array}{c}\text { Taiwan's } \\
\text { Global } \\
\text { Market } \\
\text { Share } \\
\end{array}$ & Items & $\begin{array}{c}\text { Taiwan's } \\
\text { Global } \\
\text { Market } \\
\text { Share } \\
\end{array}$ \\
\hline 1. Foundry (1) & 66.0 & 1. PNDs (1) & 39.5 & 1. Ball screw(1) & 18.0 \\
\hline 2. Optical dises (1) & 61.6 & 2. IC substrate (1) & 25.1 & 2. PCBs (1) & 16.4 \\
\hline 3. IC packaging \& testing(1) & 52.1 & 3. TFT-LCD panels (>10") (1) & 22.4 & 3. PTA (2) & 10.0 \\
\hline 4. Chlorella (2) & 47.0 & 4. TFT-LCD panels ( $\left.\leqq 10^{\prime \prime}\right)(1)$ & 20.8 & 4. Nylon fiber (2) & 8.3 \\
\hline 5. Glass fiber (2) & 29.2 & 5. Electro-deposited copper foil (2) & 20.0 & 5. TPEs (2) & 8.2 \\
\hline & & 6. IC design (1) & 17.7 & 6. Beta-carotene (2) & 5.0 \\
\hline & & 7. $\mathrm{ABS}(2)$ & 16.8 & 7. Polyester filament (2) & 3.5 \\
\hline & & 8. TN / STN LCD panels (1) & 16.5 & 8. WLAN (1) & 1.2 \\
\hline & & 9. Crystalline silicon solar cells(2) & 14.9 & & \\
\hline & & $\begin{array}{l}\text { 10. Power wheelchairs \& power } \\
\text { scooter(2) }\end{array}$ & 9.5 & & \\
\hline & & 11. OLED panels(1) & 5.8 & & \\
\hline
\end{tabular}

Fuente: "Taiwán Statistiscal Data Book 2013" del CEPD, Taiwán, página 13

Taiwán es un gran mercado para algunos productos que el Perú exporta. Por ejemplo, en el año 2012 importó por un total de 14,672 millones de dólares en productos agrícolas, ganaderos, pesqueros y forestales. Solo en productos pesqueros importó ese año por 1,186 millones de dólares. De Taiwán estar en el TPP, el Perú podría lograr que algunas barreras que Taiwán tiene contra la importación de algunos de esos productos, y los aranceles que aun mantiene, puedan reducirse o eliminarse.

El 2013 el comercio del Perú con Taiwán fue de 211.2 millones de dólares de exportaciones y 442.3 millones de dólares de importaciones. En el 2012 Perú había exportado por 251 millones de dólares e importado por 442 millones de dólares de Taiwán ${ }^{36}$. En el año 2013 Taiwán ocupó el 25to lugar como destino de nuestras

36 Ver estadísticas de Aduanas del Perú: http://www.aduanet.gob.pe/aduanas/informae/BalContiZonaPais_01122013.htm 


\section{Carlos Aquino Rodríguez}

exportaciones, y los 10 principales productos que le vendimos fueron cátodos de cobre, gasolina, harina de pescado, cinc sin alear, concentrados de cobre, alambre de cobre, barras de cobre, uvas, chapas y tiras de cobre, y oxido de cinc. Entre los productos importados de Taiwán más importantes fueron politereftalato de etileno, soportes ópticos sin grabar, teléfonos móviles, dispositivos de almacenamiento de datos, cámaras fotográficas digitales (según estadísticas de Aduanas del Perú).

Taiwán es un gran inversor en el extranjero, principalmente invirtiendo en Asia, como se vio en el caso de China. No hay inversión registrada de Taiwán en Proinversión, que ve la inversión extranjera en nuestro país. Pero de acuerdo a cifras proporcionadas por la Oficina Económica y Cultural de Taipéi en Lima, hay un stock de 140 millones de dólares de inversión taiwanesa en el país. Esta se encuentra principalmente en los sectores construcción, turismo, inmobiliaria, minería, y en el sector comercio, de importación de autopartes por ejemplo ${ }^{37}$.

Taiwán ha contribuido bastante al Perú ya sea a través de donaciones a instituciones del gobierno, privadas, y becas a estudiantes para las Universidades en Taiwán ${ }^{38}$. Por ejemplo, dentro del proyecto del foro APEC, el Apec Digital Opportunity Center, ADOC, Taiwán donó 16 de esos centros a nivel nacional, de los cuales 8 están en Lima, la capital, donde se tienen computadoras, se enseña cursos para su correcto uso, para enseñar programas, etc. Algunos de estos están por ejemplo en ADEX, Cámara de Comercio de Lima, Promperú. De acuerdo a información del web site de este proyecto, del 2005 a setiembre del 2012, 13 ADOC Centers se establecieron en Perú y 79,248 personas han recibido entrenamiento ahî ${ }^{39}$.

Hay interés de Taiwán y varios países en Asia en la Alianza del Pacífico, donde están aparte del Perú, Colombia, Chile y México. Chile y México son también miembros del TPP, así que el ingreso de Taiwán al TPP significaría una mayor posibilidad de negocios de los miembros de la Alianza del Pacífico con una economía muy competitiva en Asia como es Taiwán.

37 Según la entrevista concedida por Elena Yaling Chen, de la División Económica, de la Oficina Económica y Cultural de Taipéi en Lima, el día 14 de marzo del 2013.

38 Personalmente el autor de esta nota ha enviado varios de sus estudiantes de la Universidad Nacional Mayor de San Marcos becados a la Universidad Nacional de Chengchi y a la Universidad de Tamkang.

39 ADOC Portal, Perú: http://www.apecdoc.org/site/pmes/peru-pme/ 


\section{Pensamiento Crítico Vol. 19. N I}

Taiwán tiene, por otro lado, una agenda interna que cumplir para convencer a los sectores que se oponen a una mayor apertura de su economía que significará el entrar al TTP, especialmente en los sectores agrario y pecuario, la reforma y privatización de empresas estatales, y el de servicios. Taiwán tiene que hacer reformas para seguir siendo competitiva, así que la entrada al TPP también serviría para impulsar esas reformas.

En todo caso, Taiwán está preparando un estudio para ver los beneficios y costos de su entrada al TPP y se espera que para julio esté listo y pueda pedir por esa fecha su entrada.

Lo ideal sería que Taiwán ingrese al TPP antes que las negociaciones entre los miembros actuales para alcanzar un acuerdo terminen. De ingresar después, Taiwán se encontraría con reglas ya hechas y su capacidad de negociar sería mínima. Las negociaciones en el TPP continúan y se espera puedan terminar este año.

\subsection{Sobre el interés de China en el TPP}

Algo que se comenta es que China podría estar interesada también en unirse a este grupo, pues aunque este país protege aún a ciertos sectores de su economía y se verían afectados al unirse al TPP, estaría considerando las ganancias de sus sectores que sí son competitivos y que podrían acceder a mercados más grandes y abiertos. También en China se piensa que al no participar en el TPP se estaría marginando y aislando de pertenecer a un gran grupo económico, dejando el campo libre a otros países como EE.UU. y Japón. China también se estaría quedando fuera de las negociaciones para definir las nuevas reglas del comercio internacional, más abiertas, que se supone aspira el TPP. Se considera que el TPP tendría un acuerdo con estándares de alta calidad, pues habría pocas áreas o sectores sensibles fuera del proceso de liberalización.

En todo caso, este año 2014 las reuniones del foro APEC se están realizando en China, así que el debate interno para que este país pueda unirse al TPP se acrecentará ${ }^{40}$.

40 Desde el año 2013 en China discuten la conveniencia de entrar o no al TPP. Ver por ejemplo una entrevista que me hicieron sobre esto en octubre pasado, publicado en algunos medios chinos, bajo el titulo "Las negociaciones del TPP en Bali se enfrentan a un dilema" http://world.people.com.cn/n/2013/1006/ c369582-23111473.html 


\section{Carlos Aquino Rodríguez}

China, sin embargo, tendría que reformar varios sectores de su economía para poder entrar al TPP, eliminando y/o reduciendo las variadas barreras que tiene a los bienes y servicios del extranjero. Por ejemplo, en el tema de los filmes del extranjero tiene una cuota de mercado para ello. Solo permite que se exhiban 34 películas extranjeras al año, y que las películas de EE.UU. solo recauden el $25 \%$ del ingreso por la exhibición de esos films en China. Esto a pesar de que China tuvo el segundo mercado cinematográfico más grande del mundo en el 2013 después de EE.UU., con ingresos por 3.6 mil millones de dólares ${ }^{41}$.

La entrada de China al TPP sería una gran ganancia para este grupo pues es la segunda economía más grande del mundo y muchos miembros del TPP tienen a China como su mayor socio comercial (por ejemplo Chile y Perú). Con China en el TPP este grupo se volvería el más grande en el mundo con la mayor población, volumen de comercio y tamaño económico.

Para China, los miembros del TPP constituyeron el 33\% de su comercio el año 2013 y varios de sus socios más importantes son miembros del TPP.

Pero, como se dijo, no será fácil para China aceptar las reglas del TPP o implementar las reformas para liberalizar muchos sectores de su economía y abrirlos a la competencia extranjera. También la posible entrada de China hará las negociaciones con los miembros del TPP probablemente más largas de lo que es ahora con Japón.

China es un recién llegado al mundo de los tratados de libre comercio. Justo después que entró a la OMC en el 2001, China empezó a firmar TLC con socios en Asia y fuera de esta región, al punto que este país, que hasta hace 35 años tenía un mercado cerrado al mundo con una economía estatal, ahora tiene más TLC en Asia que Japón y Corea, países con economías capitalistas desde mucho antes.

Una razón por la que podría ser bueno para China unirse al TPP es que al hacer esto el país se vería forzado a hacer reformas más rápido y ser más eficiente. Se dice que esto tendría el mismo efecto que cuando China se unió a la OMC en el 2001. China acordó abrir más su economía en esa fecha. Otra razón por la cual podría ser bueno para China unirse al TPP es que, quizás no ahora, pero conforme China avanza en la cadena de valor agregado,

41 Ver BBC News "China retains grip on foreign film quota" http://www.bbc.co.uk/news/entertainmentarts-26152190 


\section{Pensamiento Crítico Vol. 19. N I}

ya no será solo el lugar donde muchas partes y componentes producidos en otros países son ensamblados para convertirse en un producto final, sino que China producirá partes y componentes que se ensamblarán en lugares donde la mano de obra sea más barata, como Vietnam, o Indonesia, u otros países del TPP. Si este es el caso y China no está en el TPP, sus partes y componentes se verán excluidos de los beneficios de las reglas de origen que favorecen el uso de partes y componentes producidos dentro del TPP (esta es la razón por la que Corea y Taiwán se preocupan de no quedar excluidos de las cadenas de valor que se forman entre los miembros del TPP y por eso quieren unirse a este grupo).

En todo caso, China está considerando los efectos positivos y negativos de su participación en el TPP y será interesante ver la conclusión a la que llegue.

\section{El TPP y el futuro del APEC}

El foro APEC, creado en 1989, se planteó en 1994 el objetivo de que para el año 2010 los miembros más adelantados del grupo, EE.UU., Japón, Canadá, Australia, Nueva Zelanda, puedan abrir sus mercados al resto de las economías miembros, y que para el 2020 haya entre todos los miembros un área libre para el comercio e inversiones. Como esto no está avanzando como debería ser, la meta del 2010 por ejemplo no se ha cumplido, se piensa que el TPP, al ir sumando poco a poco más miembros del APEC, podría alcanzar el objetivo último del foro APEC. Se habla de crear una Zona de Libre Comercio del Asia Pacífico, o FTAAP por sus siglas en ingles, Free Trade Area of the Asia Pacific, entre todos los miembros del foro APEC. Un TPP que incluya a todos los miembros del APEC sería ese FTAAP.

Algo que se toma en cuenta cuando se habla de acuerdos de integración económica en el Asia Oriental es el de la Asociación Económica Regional Global, o RCEP, que es un grupo que busca tener el año 2015 un acuerdo integral de comercio e inversiones. Lo integran el grupo de 10 países del ASEAN o la Asociación de Naciones del Sudeste Asiático (Association of South East Asian Nations), con 6 países más: Australia, China, Corea de Sur, India, Japón y Nueva Zelanda. ASEAN ya tiene TLC con cada uno de estos 6 países.

Los 10 miembros del ASEAN son Brunéi, Camboya, Filipinas, Indonesia, Laos, Malasia, Myanmar, Tailandia, Singapur y Vietnam. De estos, 7 son miembros del foro APEC (no lo son Camboya, Laos y Myanmar). 


\section{Carlos Aquino Rodríguez}

Se dice que este RCEP puede ser también, junto con el TPP, un camino para alcanzar un acuerdo de integración económica completa en el Asia Pacífico, aunque en el RCEP no hay ningún país del otro lado del Pacífico. También se dice que el RCEP es liderado por China, por su tamaño, en contraposición al TPP que es liderado por EE.UU.

Pero en verdad parece un poco difícil que el RCEP logre alcanzar en el futuro mediato un acuerdo de liberalización profunda o de alta calidad, pues muchos países presentes ahí, por mencionar solo dos, India y China, tienen muchos sectores de su economía protegidos, así que el TPP podría ser el que pueda primero alcanzar el objetivo final del APEC.

Habría que recordar también que China, Corea y Japón están negociando un Tratado de Libre Comercio entre ellos ${ }^{42}$. Esto es importante pues son las tres economías más grandes del Asia Oriental, donde Japón y Corea son las economías más industrializadas.

\section{Conclusiones}

Para el Perú, el hecho de estar en el TPP presenta la oportunidad de acceder, con menos barreras, a varios de los mercados más grandes en el mundo. Es posible que a los 12 miembros actuales, se sumen otros más, como Corea, Taiwán y China. De esta forma el TPP iría incluyendo a la mayor parte de los miembros del foro APEC y cumpliría el objetivo de este de alcanzar para el 2020 un área de libre comercio e inversiones. Queda para el Perú aprovechar más estos acuerdos con una oferta exportable mayor, atrayendo más inversión extranjera, fortaleciendo su infraestructura física y humana para poder tener industrias que puedan darle más valor agregado a las materias primas que son las que mayormente exportamos ahora.

En abril el presidente de EE.UU., Barack Obama, visitó Japón, Corea del Sur, Malasia y Filipinas y se vio el tema del TPP, entre otros, pero no se alcanzó un avance significativo ${ }^{43}$.

La posible inclusión de nuevos miembros, como Corea del Sur y Taiwán, sería posible este año antes de que acaben las negociaciones. Corea quizás estaría más cerca de ser admitido, pues el tema con Taiwán es que tendría que haber una decisión más política que económica para su admisión, teniendo en cuenta el factor de China. Este

42 Ver Post "China, South Korea, Japan to hold FTA talks" http://post.jagran.com/china-south-korea-japan-to-hold-fta-talks-1393321904

43 Ver EIR: "Obama's Failed Asia Trip: Nothing Left But War" http://www.larouchepub.com/ other/2014/4118obama_trip_war_asia.html 


\section{Pensamiento Crítico Vol. 19. N I}

último debate su entrada al TPP, aunque para entrar tendría que hacer reformas a muchos sectores de su economía protegidos de la competencia extranjera.

Para Taiwán es una necesidad el entrar al TPP, pues esto le permitirá seguir siendo competitivo y no quedarse detrás de sus rivales como Corea y Singapur, y también no

quedar excluido de las cadenas de valor que se forman entre los países del TPP, así como le haría más fácil entrar a otros acuerdos como el RCEP, le serviría también para impulsar sus reformas domesticas, en su economía, y para poder competir también con China y evitar depender de este.

China considera los méritos y deméritos de entrar al TPP y será interesante ver a que decisión llega.

\section{Referencias bibliográficas}

Aduanas del Perú: Estadisticas de comercio exterior: http://www.aduanet.gob.pe/ aduanas/informae/BalContiZonaPais_01122013.htm

APEC Digital Opportunity Center, ADOC Portal, Perú: http://www.apecdoc.org/site/ pmes/peru-pme/

Carlos Aquino Rodriguez:"El rol de China en la economía asiática e implicancias para la economía mundial", Revista Pensamiento Crítico de la Facultad de Ciencias Económicas de la Universidad Nacional Mayor de San Marcos, Vol. 18, №. 1, junio 2013, págs. 7 al 42

The Brooking Institution Center for East Asia Policy Studies:"Taiwan and the Trans-

Pacific Partnership: Preparing the way": http://www.brooking.edu/ /media/research/ files/papers/2013/10/taiwan\%20transpacific\%20partnership\%20bush\%20meltzer/ taiwan\%20and\%20tpp\%20bush\%and\%20meltzer\%20103013.pdf

Council for Economic Planning and Development, CEPD:"Taiwán Statistical Data Book 2013"

Diario Gestión: varios números

Nikkei Asian Review: http://asia.nikkei.com/magazine/

World Trade Online: http://insidetrade.com/ 